\title{
Prospects dim for agreement on new climate targets
}

\section{Switzerland seeks greater role in EC research projects}

London. The chances of reaching international agreement in the near future on binding targets for a long-term reduction in greenhouse gas emissions are rapidly diminishing. Few now expect the countries that signed the United Nations Framework Convention on Climate Change (FCCC) in Rio de Janeiro in 1992, which hold their first full post-Rio meeting in Berlin at the end of March, will agree such a goal.

As delegates gathered in New York last Monday (6 February) for their final preparatory meeting - referred to as Intergovernmental Negotiating Committee (INC) 11 the most that supporters of binding reduction targets were expecting was a pledge to begin negotiations on a post-2000 protocol. Developed countries may also agree to adopt an interim goal of stabilizing $\mathrm{CO}_{2}$ emissions after 2000 at 1990 levels.

The commitment enshrined in the treaty signed at the 'Earth Summit' was that such countries should aim to return their greenhouse gas emissions to 1990 levels by the year 2000. This was to be the first step towards the ultimate objective of stabilizing greenhouse gas concentrations in the atmosphere at a sufficiently low level to prevent dangerous interference with the climate system (see Nature 371, 274; 1994).

But the measures introduced by most countries so far seem to be falling short of their targets. According to an analysis by the interim secretariat of the FCCC of the 15 country programmes received so far, only five countries are expected to return to 1990 $\mathrm{CO}_{2}$ levels or less by the year 2000 without additional measures.

Nevertheless, many countries are confident that they will meet the targets. Rafe Pomerance, deputy assistant secretary for environment and development in the bureau of oceans and international environmental and scientific affairs in the US State Department, says that voluntary measures in the US programme are only just starting to take off. "The President has made a commitment to return to 1990 levels by the year 2000 so that's our national commitment."

A handful of European Union (EU) countries are likely to achieve the target among them the United Kingdom, but the EU as a whole seems unlikely to do so. Nevertheless, the 12 environment ministers of the EU have joined other countries in stating that the current commitment is inadequate to achieve the main objective and must be strengthened.

This so-called review of the "adequacy of commitment" is likely to be one of the more contentious issues discussed at Berlin, particularly as the Intergovernmental Panel of Climate Change (IPCC)'s Special Report was officially launched on the first day of INC 11. The report reiterates earlier conclusions by the IPCC that stabilization of greenhouse gas emissions at 1990 levels will not stabilize atmospheric concentrations at nondangerous levels.

But the EU ministers drew back from giving their full support to a proposal for a draft protocol, already tabled by Trinidad and Tobago on behalf of the Alliance of Small Island States, which commits signatories to the so-called 'Toronto Target'. This specifies a goal of at least 20 per cent reductions of anthropogenic emissions of $\mathrm{CO}_{2} \mathrm{com}-$ pared to 1990 levels by the year 2005 .

Instead, the ministers decided to seek agreement for stabilization of $\mathrm{CO}$, emissions and to begin negotiations on how the commitment could be extended, with a view to adopting a protocol at the third confer-

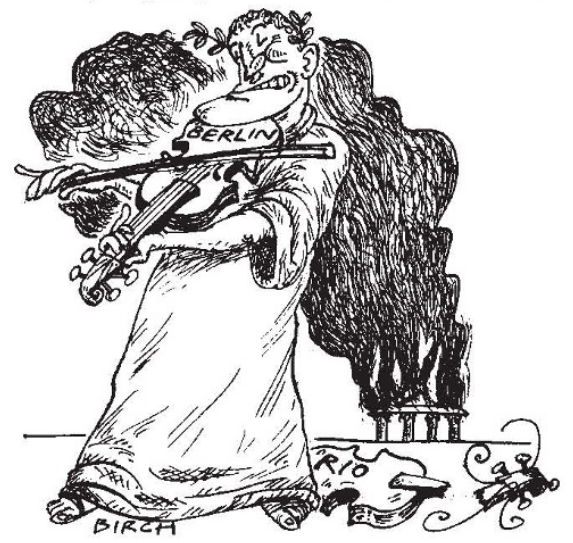

ence of parties in 1997. The United States is also known to be in favour of starting negotiations on a draft protocol.

This 'worst-case scenario' has caused dismay among environmental groups. Matthew Spencer, atmosphere campaigner for Greenpeace UK, says that if this stance is adopted at Berlin the signatories of the treaty will be no further forward than they were at Rio. Environmental groups and developing countries all interpret the FCCC as committing developed countries stabilizing emissions after the year 2000

Meanwhile, the United States announced last week its first 'joint implementation' programmes under which it will help to finance a project designed to help reduce the emission of greenhouses gases in a third world country.

Although the principles behind such agreements are opposed by some environmentalists, who claim that they could become an unacceptable substitute for domestic measures, US officials claim that joint implementation projects have "a great potential", and are keen to support such projects in Berlin.

Maggie Verrall
Berne \& Munich. Switzerland has opened negotiations with the European Commission (EC) that could lead to Swiss scientists playing a more active role in the EC's fourth Framework programme, which started on 1 January and runs to 1999 .

But the talks may not be concluded in time for scientists to participate as fully as many would like, as research is only one of several items in a complex package of issues under negotiation concerning political relations between the European Union (EU) and Switzerland.

Switzerland lost its automatic right to participate fully in the Framework programme when its citizens voted against joining the European Economic Area (EEA) proposed by the government as a prelude to EU membership — in a referendum in 1992 (see Nature 370, 241; 1994).

Last year, the EU decided that Swiss scientists could pay to take part in the fourth Framework programme, but only on a project-by-project basis, and under strict conditions. Unlike scientists in EU states, for example, Swiss scientists cannot become members of the decision-making programme committees. They are also required to team up with partners in two EU member countries to take part in a project, and cannot become project leaders.

"These are big disadvantages for Swiss scientists because they do not have the chance to influence the direction of European research," says Tim Guldimann, a member of the group that advises the Swiss government on science and research policy.

Switzerland is now negotiating to become an associate member of the programme, at a cost of SFr200 million (US\$155 million) a year. This would give Swiss scientists access to the results of all Framework research projects, and the right to initiate and lead research projects with only one EU partner. Switzerland also wants its associate membership to give Swiss scientists the right to participate in the discussions of all programme committees. But this issue remains more controversial.

The EC is insisting that countries that are members of neither the EU nor the EEA cannot have observer or participant status. It has suggested a bilateral committee between Switzerland and the EU at which matters relating only to Switzerland are discussed.

The outcome of the negotiations could be delayed because they are linked to four other issues as a single package. This is bound to slow down the talks, says Jakob Kellenberger, who is leading the negotiations for Switzerland, and who would like each issue to be considered separately.

Oliver Klaffke \& Alison Abbott 